\title{
The intrauterine and early postnatal origins of cardiovascular disease and chronic bronchitis
}

\author{
D J P BARKER, C OSMOND, AND C M LAW \\ From the MRC Environmental Epidemiology Unit, University of Southampton, Southampton General Hospital, \\ Southampton.
}

ABSTRACT Geographical differences in mortality from cardiovascular disease and chronic bronchitis within England and Wales are closely related to past differences in infant mortality. This paper examines the separate relations of mortality during 1968-78 with neonatal and post-neonatal mortality during 1911-25. These divisions of infant mortality are indicators of the intrauterine and early postnatal environments respectively. Stroke is related to neonatal mortality and therefore to the intrauterine environment. Prenatal determinants of blood pressure levels may be one mechanism underlying this. Bronchitis is related to postnatal mortality and therefore to the postnatal environment. This may reflect the long term effects of lower respiratory tract infection in early childhood. Ischaemic heart disease is related to both neonatal and post-neonatal mortality and therefore to the intrauterine and postnatal environments. The links may include blood pressure and as yet unknown processes established in early postnatal life.

Within England and Wales there is a close relation between geographical differences in mortality from cardiovascular disease and differences in infant mortality 70 and more years ago. ${ }^{1}$ A similar relation between current cardiovascular mortality and past infant mortality has been shown within three other countries: in the 20 counties of Norway, ${ }^{2}$ in east and west Finland, ${ }^{3}$ and in 17 registration states within the United States of America. ${ }^{4}$

The data from England and Wales are based on the largest numbers of deaths. They allow detailed examination based on the 212 local authority areas into which the country was formerly divided, and they allow analyses for ischaemic heart disease and stroke separately. The completeness and detail of infant mortality records from 1911 onwards enable examination of the relations with infant mortality at different ages and from different causes. In particular they distinguish neonatal mortality (deaths before 1 month of age) from post-neonatal mortality (deaths from 1 month to 1 year).

Findings in Norway and Finland were interpreted as evidence that adverse living conditions during childhood, for example housing and recurrent infection, increased the risk of ischaemic heart disease. $^{23}$ The study in the USA found a closer relation with infant mortality from diarrhoeal disease than from other causes. ${ }^{4}$ In our first analysis we found that whereas the geographical correlations of cardiovascular disease with previous neonatal and post-neonatal mortality rates were similar when expressed as correlation coefficients, the position of the 15 London boroughs on the scattergram suggested a more consistent relation with neonatal mortality. ${ }^{1}$ London has low cardiovascular mortality and had low neonatal mortality but high post-neonatal mortality in the past.

Seventy years ago most neonatal deaths occurred within a week of birth and depended mainly on prenatal rather than postnatal influences. 5 This pointer to a relation with the intrauterine environment is reinforced by the relation between cardiovascular disease and past maternal mortality, a relation which is especially strong for stroke. ${ }^{6}$

We present here an analysis which discriminates more closely between the geographical relations of cardiovascular disease with past neonatal and posneonatal mortality. The findings are contrasted with those for chronic bronchitis, where the geographical distribution is closely related to past variations in post-neonatal mortality from respiratory infection and is therefore determined by the postnatal environment. ${ }^{7}$ Lower respiratory tract infections in infancy and early childhood are a known risk factor for chronic bronchitis. 


\section{Methods}

Numbers of neonatal deaths and of post-neonatal deaths in different areas of England and Wales were published from 1911 onwards. $^{8}$ We calculated rates per 1000 births for 1911-25. During this time there were 436087 neonatal deaths and 668115 postneonatal deaths.

The Office of Population Censuses and Surveys made available extracts from all death certificates in England and Wales during 1968-78, the period covered by the eighth revision of the International Classification of Diseases (ICD). ${ }^{9}$ Our analysis is based on mortality at ages 35-74. Sex specific rates were based on data from the 1971 census and were expressed as standardised mortality ratios (SMRs). Stroke was defined as ICD $431-438$, which is cerebrovascular disease other than subarachnoid haemorrhage. Ischaemic heart disease was defined as ICD 410-414 and chronic bronchitis as ICD 490-492.

We analysed mortality in the 212 local authority areas used by the Registrar General since 1911-that is, 80 county boroughs (larger towns), 15 London boroughs, 59 urban areas (metropolitan boroughs and urban districts) within counties, and 58 rural areas. We ordered the areas according to neonatal mortality during 1911-25 and derived five groups of 42 or 43 areas with increasing mortality. We similarly derived five groups with increasing post-neonatal mortality. In this way mortality at ages 35-74 was examined within a grid of 25 cells.

\section{Results}

Table 1 shows the numbers of areas of England and Wales within each neonatal and post-neonatal mortality group. Neonatal mortality rose from 30 per 1000 births in group 1 to 44 in group 5. Post-neonatal mortality rose from 32 per 1000 in group 1 to 73 in group 5. Most areas were on the diagonal of the grid.

Table 1 Division of the 212 areas of England and Wales according to neonatal and post-neonatal mortality during 1911-25.

\begin{tabular}{|c|c|c|c|c|c|c|}
\hline & \multicolumn{5}{|c|}{$\begin{array}{l}\text { Post neonatal mortality } \\
\text { lowest }\end{array}$} & \multirow{2}{*}{$\begin{array}{l}\text { Neonatal } \\
\text { deaths per } \\
1000 \text { birth }\end{array}$} \\
\hline & 1 & 2 & 3 & 4 & 5 & \\
\hline \multicolumn{7}{|l|}{ Neonatal mortality } \\
\hline 1 lowest & 21 & 11 & 5 & 4 & 1 & 30 \\
\hline 2 & 11 & 16 & 9 & 5 & 2 & 33 \\
\hline 3 & 8 & 11 & 14 & 5 & 4 & 36 \\
\hline 4 & 0 & 5 & 11 & 18 & 9 & 39 \\
\hline 5 highest & 2 & 0 & 3 & 11 & 26 & 44 \\
\hline \multicolumn{7}{|l|}{ Post-neonatal } \\
\hline $\begin{array}{l}\text { deaths per } \\
1000 \text { births }\end{array}$ & 32 & 40 & 50 & 61 & 73 & \\
\hline
\end{tabular}

Areas with low neonatal but high post-neonatal mortality were mostly in London but included the county boroughs of Chester and Great Yarmouth. Areas with high neonatal but low post-neonatal rates were scattered through the north and west and included the rural areas of Anglesey, Northumberland and Staffordshire.

Table 2 shows mortality from stroke, ischaemic heart disease and chronic bronchitis within the grid defined in table 1. Within any of the five bands of post-neonatal mortality, standardised mortality ratios for stroke increased sharply with increasing neonatal

Table 2 Death rates from stroke, ischaemic heart disease and chronic bronchitis (SMRs, ages 35-74, both sexes, 1968-78) in the 212 areas of England and Wales grouped by neonatal and post-neonatal mortality (1911-25).

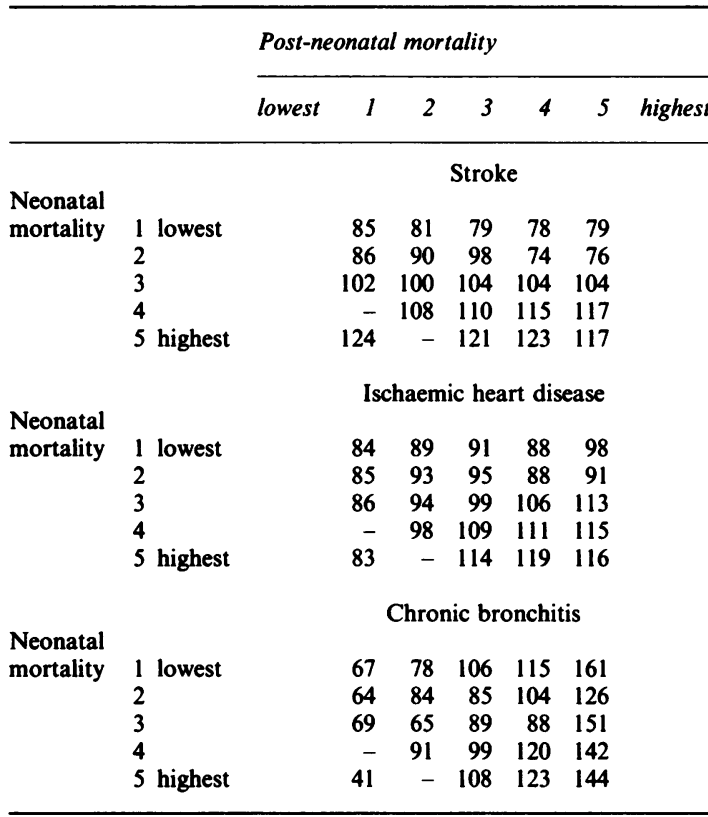

mortality. There was no independent trend in stroke mortality with post-neonatal mortality. Mortality from ischaemic heart disease had similar but separate trends with neonatal and post-neonatal mortality. Mortality from chronic bronchitis showed a steep increase with increasing post-neonatal mortality, but no independent trend with neonatal mortality.

\section{Discussion}

This analysis shows that mortality from cardiovascular disease and chronic bronchitis has different geographical relations with past differences in the intrauterine and early postnatal environments, 
as indicated by the distribution of neonatal and post-neonatal mortality in England and Wales during 1911-25. Stroke is related to the intrauterine environment; chronic bronchitis is related to the postnatal environment; and ischaemic heart disease is related to both.

The median year of birth of people dying before 75 years of age during 1968-78, the years included in our analysis, is around 1905. The data on infant mortality are for 1911-25 and do not exactly correspond with this. Data published before 1911, however, do now allow such a detailed geographical analysis. The distributions of neonatal and post-neonatal mortality changed little throughout 1911-25, despite a fall in the rates, and there is no reason to think that they differed much from those in the previous decade.

We have suggested that blood pressure is one link between an adverse intrauterine environment and the risk of cardiovascular disease. ${ }^{6}$ In two large national samples of people in Britain, one comprising adults age 36 years and the other children aged 10 , blood pressure was inversely related to birth weight. ${ }^{10}$ In the past most neonatal deaths in Britain occurred during the first week after birth and were attributed to prematurity or low birth weight. ${ }^{5}$ The geographical distribution of maternal mortality, from causes other than puerperal fever, was closely similar to neonatal mortality. Poor physique of the mothers was clearly implicated as a cause of high maternal mortality, and was itself a result of poor nutrition and impaired growth of young girls. ${ }^{11}$ The aggregation of high perinatal mortality, low birth weight and poor maternal physique in certain areas of the country was first shown in national surveys during 1910-30, and has been repeatedly confirmed in perinatal surveys since the second world war. ${ }^{12}$ The magnitude of past differences in birth weight is illustrated by the birth weight distribution of babies born in maternity hospitals in Preston and London around 1930. In Preston, which had high neonatal and maternal mortality, mean birth weight was 289 grams below that in London, which had low mortality (unpublished data).

A number of mechanisms could link an adverse intrauterine environment, reduced fetal growth and higher blood pressure. Pressure in the fetal circulation could be elevated as a method of maintaining placental perfusion, and the elevated pressures may persist after birth. ${ }^{13}$ Retardation of intrauterine growth may lead to accelerated postnatal growth accompanied by an accelerated increase in blood pressure. ${ }^{14}$

There is considerable evidence linking serious or recurrent lower respiratory tract infection before the age of 2 years with increased risk of chronic bronchitis in adult life, though the mechanism underlying this association is not understood. ${ }^{1516}$ Part of this evidence comes from the remarkably close and specific geographical relation between past infant mortality from bronchitis or pneumonia and current mortality from chronic bronchitis in England and Wales. ${ }^{7}$

The distribution of ischaemic heart disease correlates more closely with past infant respiratory mortality than with other leading causes of postneonatal death. ${ }^{1}$ A pulmonary lesion could be the link between an adverse early postnatal environment and risk of ischaemic heart disease. A reduced forced expiratory volume in middle life is associated with an increased risk of myocardial infarction. ${ }^{17}$ Failure of long term "programming" of lipid metabolism during infancy, as a result of infant feeding, is another possible link between infancy and ischaemic heart disease for which there is increasing evidence in experimental animals. ${ }^{18}$

Mortality from stroke has fallen in Britain over the past 40 years. $^{7}$ This is consistent with past improvements in the intrauterine environment, as a result of improved maternal physique. Bronchitis mortality has also fallen, in keeping with past improvements in housing and reduction of overcrowding. Ischaemic heart disease mortality, however, has risen steeply. It may therefore have two groups of causes, one acting through the mother and in infancy, and associated with poor living standards, the other acting in later life, and associated with affluence.

Address for correspondence and reprints: Professor D J P Barker, MRC Environmental Epidemiology Unit, University of Southampton, Southampton General Hospital, Southampton SO9 4XY, UK.

\section{References}

${ }^{1}$ Barker DJP, Osmond C. Infant mortality, childhood nutrition and ischaemic heart disease in England and Wales. Lancet 1986; i: 1077-81.

2 Forsdahl A. Are poor living conditions in childhood and adolescence an important risk factor for arteriosclerotic heart disease? Br J Prev Soc Med 1977; 31: 91-5.

${ }^{3}$ Notkola V. Living conditions in childhood and coronary heart disease in adulthood. Helsinki: Finnish Society of Science and Letters, 1985.

${ }^{4}$ Buck C, Simpson H. Infant diarrhoea and subsequent mortality from heart disease and cancer. $J$ Epidemiol Community Health 1982; 36: 27-30.

${ }^{5}$ Local Government Board. Thirty-ninth annual report 1909-10. Supplement on infant and child mortality. London: HMSO, 1910.

${ }^{6}$ Barker DJP, Osmond C. Death rates from stroke in England and Wales predicted from past maternal mortality. Br Med J 1987; 295: 83-6.

${ }^{7}$ Barker DJP, Osmond C. Childhood respiratory infection and adult chronic bronchitis in England and Wales. $\mathrm{Br}$ Med J 1986; 293: 1271-5.

${ }^{8}$ General Register Office. Registrar General's statistical reviews of England and Wales 1911 et seq. Part 1. Tables, medical. London: HMSO, 1911 et seq. 
${ }^{9}$ Gardner MJ, Winter PD, Barker DJP. Atlas of mortality from selected diseases in England and Wales 1968-78. Chichester: John Wiley, 1984.

${ }^{10}$ Barker DJP, Osmond C, Golding J, Kuh D, Wadsworth MEJ. Growth in utero, blood pressure in childhood and adult life, and mortality from cardiovascular disease. $\mathrm{Br}$ Med J 1989; 298: 564-7.

${ }^{11}$ Campbell JM, Cameron D, Jones DM. High maternal mortality in certain areas. London: HMSO, 1932. (Ministry of Health Reports on Public Health and Medical Subjects, No. 68).

12 Butler N, Alberman ED. Second report on the 1958 British perinatal mortality survey. Edinburgh and London: Livingstone, 1969.

${ }^{13}$ Gennser G, Rymark P, Isberg PE. Low birth weight and risk of high blood pressure in adulthood. Br Med J 1988; 296: 1498-9.

14 Ounsted MK, Cockburn JM, Moar VA, Redman CWG. Factors associated with the blood pressures of children born to women who were hypertensive during pregnancy. Arch Dis Child 1985; 60: 631-5.
${ }^{15}$ Colley JRT, Douglas JWB, Reid DD. Respiratory disease in young adults: influence of early childhood lower respiratory tract illness, social class, air pollution, and smoking. Br Med J 1973; 111: 195-8.

${ }^{16}$ Holland W, Halil T, Bennett AE, Elliot A. Factors influencing the onset of chronic respiratory disease. $\mathrm{Br}$ Med J 1969; 11: 205-8.

${ }^{17}$ Cook DG, Shaper AG. Breathlessness, lung function and the risk of heart attack. Eur Heart $J$ (in press).

18 Mott GE. Deferred effects of breastfeeding versus formula feeding on serum lipoprotein concentrations and cholesterol metabolism in baboons. In: Filer $\mathbf{L J ~ J r}$, Fomon SJ, eds. The breastfed infant: a model for performance. Report of the ninety-first Ross conference on pediatric research. Columbus, Ohio: Ross Laboratories, 1986: 144-9.

Accepted for publication March 1989 